\title{
Memory for faces: Are caricatures better than photographs?
}

\author{
BARBARA TVERSKY and DAPHNA BARATZ \\ Stanford University, Stanford, California
}

\begin{abstract}
Because photographs capture an individual at a moment in time, they contain fleeting features as well as more stable ones. Caricature line drawings, however, include stable features and emphasize distinctive ones. As such, caricatures are closer to schematic memory representations than are photographs. Three experiments using faces of public figures test the hypothesis that caricatures yield better performance than do photographs. Contrary to hypothesis, photographs lead to better performance than do line-drawing caricatures in three different tasks: name recall, face recognition, and name-face verification reaction time. Photographs are also rated as more characteristic or representative of their targets than are line-drawing caricatures.
\end{abstract}

How is it that when we accidently meet a former acquaintance after many years, we are nonetheless able to recognize that person? Scenes, too, are easily recognized even when degraded or presented rapidly (Biederman, 1981). The view that knowledge of faces and scenes, like other knowledge, is represented schematically in memory has been used to explain excellent performance in such tasks (e.g., Bartlett, 1932; Biederman, 1981; Minsky, 1975; Rumelhart, 1981). The notion of a schematic representation for a category of things has been developed in different ways and given different names. One view is that a schema or prototype contains the central tendencies of a set of features (e.g., Posner \& Keele, 1968; Reed, 1973); another view is that the category is represented by the features that occur more frequently in category members (e.g., Rosch \& Mervis, 1975). In either case, category members that are closer to the prototype or more typical are more likely to be retrieved, are more rapidly identified, are more rapidly verified, and are easier to learn (e.g., Rosch, 1978).

Just as different instances of object categories vary in how typical they are of the category, different instances, in this case, photographs or drawings, of an individual can vary in how well they represent that individual. It has been suggested that a good line drawing or caricature can capture the essence of an individual better than a spontaneous photograph. This is because such a drawing enhances the distinctive features of the person depicted and underplays irrelevant or unimportant features (e.g., Gibson, 1969; Perkins, 1975). Thus, an enhanced drawing

This research was supported by grants from the Human Development Institute of the Hebrew University of Jerusalem, the Batsheva de Rothschild Fund at the Van Leer Institute, Jerusalem, Israel, and N.S.F. Grant BNS 8002012 and N.I.M.H. Grant MH-34248 to Stanford University. We are grateful to Avraham Schwartz for his enthusiasm and his wonderful drawings and to Michael Halper and Hila Lifshitz for running the memory experiments. Requests for reprints may be directed to Barbara Tversky, Department of Psychology, Building 420, Stanford University, Stanford, CA 94305. may be more typical or characteristic of its target than any single spontaneous photograph of the target, because the latter may omit more essential features, on the one hand, and include irrelevant features, on the other hand. Some support for this position comes from a widely cited study of tachistoscopic recognition. Ryan and Schwartz (1956) found that cartoon drawings were correctly interpreted at shorter exposures than were photographs.

We sought support for the hypothesis that enhanced drawings of individuals, by emphasizing important or distinctive features and deemphasizing unimportant or irrelevant features, would be closer to representations in memory than would spontaneous photographs. If caricatures are closer to memory representations than are photographs, they should lead to better memory and faster retrieval. We selected public figures who appeared quite frequently in the daily newspapers and nightly television news. An artist who had published several books of line drawings and caricatures, and who taught courses in both, provided uniform drawings. He was requested to emphasize distinctive features and to deemphasize unimportant features (he said that that is how he draws anyhow). Photographs of the same individuals were obtained independently from a national news medium. The photographs were for the most part spontaneous but professional. In the first experiment, photographs and/or drawings were presented for name recall and face recognition. Recall and recognition were both examined because certain variables, like frequency, have opposite effects on recognition and recall (Kintsch, 1970; Tversky, 1973). Also, because the name is the same for both photographs and drawings, the effects of more characteristic stimuli were expected to be attenuated or absent for name recall. To get ahead of the story, but to explain our motivation for the other experiments, which will be described together, both recognition and recall were better for photographs than for caricatures, contrary to hypothesis. We next tried a timed task: Perhaps a "superstimulus" would affect only retrieval speed and not memorability. Again, contrary to hypothe- 
sis, semantic verification was faster for photographs than for caricatures. Finally, we wondered if our initial assumption-that enhanced drawings would better represent individuals than photographs-was correct. In fact, on the average, although individual subjects thought that certain caricatures better captured particular public figures than the corresponding photographs, the photographs were judged to be better representations than the caricatures.

\section{METHOD}

\section{Stimuli}

The stimuli were faces of 44 public figures who were well known to our subject population at the time (1975-1976) from the media. For each public figure, we obtained a high-quality photograph as well as a drawing. The photographs were on slides provided by a national news medium, which wishes to remain anonymous. Because of the diversity of caricature styles present in news media, we commissioned a single artist to draw them in order to provide a uniform style to the drawings. We believed that, otherwise, differences in line width, line length, use of shading, and other stylistic variables might make it difficult for viewers to "read" the caricatures. Thus, although the photographs presumably were provided by a number of photographers, the caricatures were provided by a single artist; however, it seemed to us that news media photography is standardized more than caricature. The drawings were provided by a professional artist who had published books and taught courses in caricatures and drawings. He was asked to produce drawings or caricatures of the targets that enhanced their distinctive features, but was not shown the photographs. Slides were made of the drawings as well. Examples of photographs and drawings appear in Figure 1.
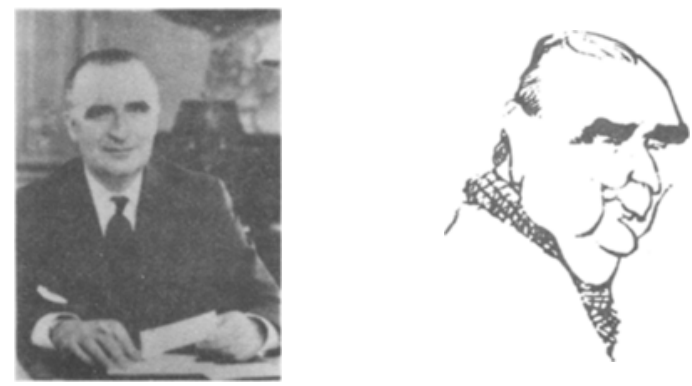

Pompidou

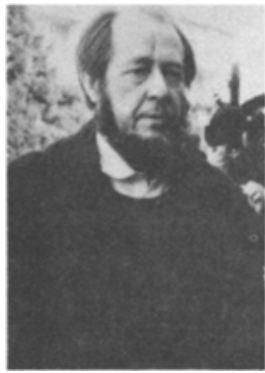

\section{Experiments}

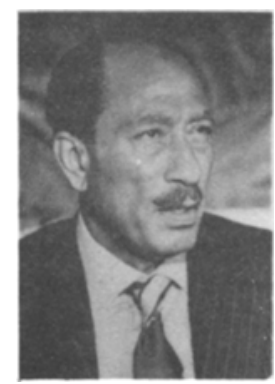

Recognition and recall. Forty of the faces were selected for the memory experiments. The four nonpolitical figures (e.g., Picasso) were eliminated so that the remaining group would be more homogeneous. Twenty of the pictures were presented for $5 \mathrm{sec}$ each in an incidental learning task, in which the subjects were requested to rate the pictures for characteristicness (see "Ratings of Characteristics," below). The subjects, students at the Hebrew University, were run in small groups in one of three conditions. In the pure-drawing condition, 20 subjects saw only drawings. Twenty subjects in the pure-photograph condition saw only photographs, and 35 subjects in the mixed condition viewed half drawings, half photographs, randomly intermixed. After the rating task, the subjects were given $5 \mathrm{~min}$ for free recall of the names of the public figures and then a yes/no recognition task in which the remaining 20 pictures were intermixed randomly with the old ones. In the puredrawing condition, the foils were drawings, in the pure-photograph conditions, the foils were photographs, and in the mixed group, the foils were half of each.

Semantic verification. Sixty-four subjects, students at the Hebrew University, participated in the experiment. For this study, slides of the pictures were paired with slides of the names of the public figures, and the subject's task was to respond "yes" or "no" as rapidly as possible depending on whether the name corresponded to the face. The subjects responded by pressing one of two levers with the right and left index fingers; for half the subjects, "yes" was on the right, and for the other half, "yes" was on the left. Half the pairs were correct, and half were incorrect, randomly intermixed. For any one subject, half the pictures were photographs and half were drawings. Across subjects, each public figure appeared equally often as a drawing and as a photograph, and within that, as correct and as incorrect. In addition, there were two randomly selected orders of presentation, each of which was executed

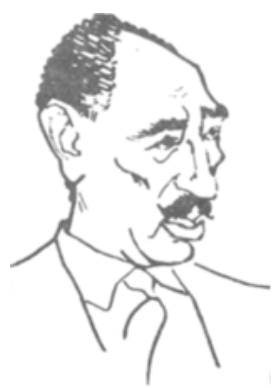

Sadat
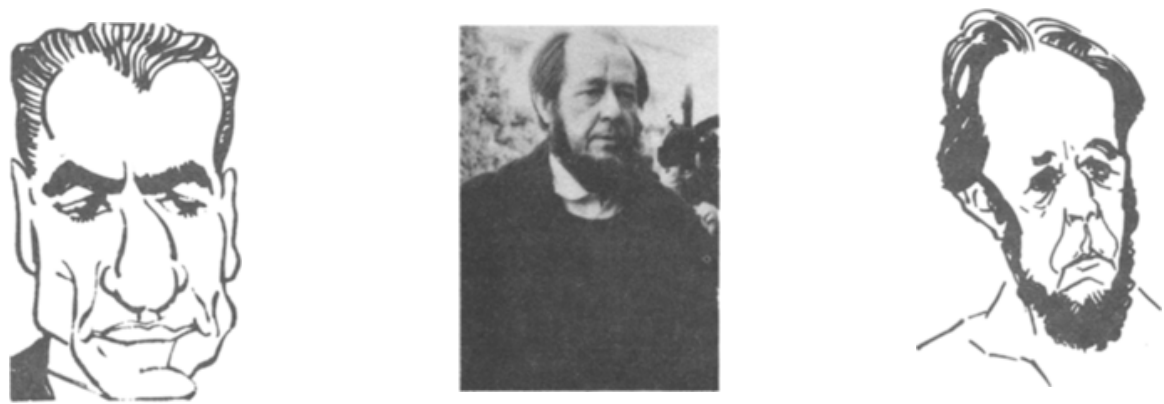

Figure 1. Examples of photographs and drawings. 
half the time in a forward direction and half the time in a backward direction.

Ratings of characteristicness. We presented the 44 photographdrawing slide pairs of the same public figure to a total of 65 subjects for representativeness ratings. The subjects, all of whom were students at the Hebrew University, were run in small groups, with order of slides and left-right position on screen counterbalanced. The instructions were to rate, on a scale from one (low) to seven (high), how typical, representative, or characteristic each picture was of the person it portrayed. The instructions, loosely translated, were as follows: "When we see a picture of an object or person, we sometimes think that the picture is not very characteristic. The picture differs from our own image of the thing or person .... If, for example, we were asked to decide which of two flowers, a daisy or a sunflower, is a more representative flower or fits our image of a flower better, a daisy would probably seem more representative even though a sunflower is also a flower. When we see a picture or drawing of a particular person, we may have the feeling that that picture is not a good likeness and that some other picture might characterize the person better. In this experiment, you will see two pictures of the same person, side by side, one a drawing, the other a photograph .... Please decide which of the two pictures better matches your image of the person, which of the two seems to you more characteristic of the person .... Rate how well each of the pictures fits your image of the person; both may be very good fits, or both may be poor fits, or one may fit well and the other not." The subjects were then requested not to simply rate how good the picture was and were instructed how to use the scale.

\section{RESULTS}

\section{Recall and Recognition}

The correlations between name recall and picture recognition were all very close to zero (and nonsignificant), replicating and extending previous research (Bahrick \& Boucher, 1968; Tversky, 1973, 1974) that had indicated that the factors making a picture recognizable may differ from the factors making its label recallable, even in an incidental learning situation and even for faces of famous people. Photographs were better recognized $[t(34)=$ $3.79, \mathrm{p}<.001]$ and recalled $[\mathrm{t}(34)=5.72, \mathrm{p}<.001]$ in the mixed group and better recognized $[t(19)=4.25$, $\mathrm{p}<.001]$ in the pure groups (Table 1). Recognition scores include both hits and correct rejections, both of which were higher for photographs than for drawings. The effect of recall in the pure groups was not significant $[\mathrm{t}(19)=1.00]$. In the incidental task, photographs were rated as more characteristic or representative of the public figures than drawings [pure groups, $\mathrm{t}(34)=5.41$, $\mathrm{p}<.01$; mixed group, $\mathrm{t}(26)=5.04, \mathrm{p}<.01]$.

Table 1

Percent Recall and Recognition of Photographs and Drawings by Subjects Viewing Only One Type (Pure) or Both (Mixed)

\begin{tabular}{lcc}
\hline Memory Test & Photographs & Drawings \\
\cline { 2 - 3 } Recall & Pure List & \\
Recognition & 47 & 42 \\
& 95 & 85 \\
Recall & Mixed List & \\
Recognition & 57 & 39 \\
\end{tabular}

Table 2

Reaction Times to Verify Picture-Name Pairs

\begin{tabular}{lcc}
\hline & \multicolumn{2}{c}{ Response } \\
\cline { 2 - 3 } Stimulus & Yes & No \\
\hline Photograph & 1.483 & 1.540 \\
Drawing & 1.553 & 1.642 \\
\hline
\end{tabular}

\section{Semantic Verification}

Errors constituted less than $4 \%$ of the data, and were eliminated from the analysis. Reaction times to verify picture-name pairs are displayed in Table 2. Responses to photographs were significantly faster than responses to drawings $[\mathrm{F}(1,63)=10.95, \mathrm{p}<.002]$, and "yes" responses were faster than "no" responses $[F(1,63)=11.79, p<.001]$. The interaction between type of picture and response was not significant.

\section{Ratings of Characteristicness}

In each of the 44 drawing-photograph pairs, the photographs received a higher rating of representativeness than the drawings. The $t$ tests comparing ratings for drawings and ratings for photographs were significant at the .05 level or more in 41 of the 44 cases.

\section{DISCUSSION}

In recognition of faces, in recall of names in mixed photograph-caricature lists, and in speed of semantic verification, performance was better for photographs than for caricatures of public figures. Furthermore, the photographs were rated as more characteristic or representative of the public figures than the caricatures. All of this is resounding evidence against the two-part hypothesis developed in the introduction: that instances that are "closer" to memory representations of categories should be remembered better or identified faster, and that enhanced line drawings or caricatures should be "closer" to the memory representations of well-known faces because drawings emphasize distinctive features and underplay unimportant ones. Because the photographs were judged to be more characteristic of the public figures than the caricatures, the evidence damages only the second part of the hypothesis, that caricatures are closer to memory representations than photographs. Thus, better instances are in fact remembered better and identified faster, but the better instances are photographs, not caricatures.

Why did the caricatures fail? One possibility is that our caricatures were not satisfactory, that another artist or group of artists might have produced better ones. However, they were of the professional quality appearing in newspapers, books, and art exhibits, and uniformity of style seemed important to preserve. Moreover, although both the caricatures and the pictures varied in quality, for not a single caricature-photograph pair did the caricature receive a higher overall rating than the photograph. In a study of transfer between photographs and caricatures of unfamiliar faces, Perkins and Hagen (1980; 
Hagen \& Perkins, 1983) also found no advantage for caricatures or for photographs; they found transfer only from one photograph to another. Another possibility is that enhanced drawings might work for objects but not for faces. This also seems unlikely to us. For an object, the contour, outline, or canonical shape is an excellent cue to its identity (Attneave, 1954; Rosch, Mervis, Gray, Johnson, \& Boyes-Braem, 1976). One of the special aspects of faces seems to be that internal features, such as eyes, brows, mouth, and their relative positions, are more important cues to the identity of a person than are features of overall shape. Since overall shape changes with haircut, beard, hats, and the like, it would not be a very reliable cue to identity. Overall shape would inform us that this is a person, as opposed to some other kind of object, but we usually demand identification at a finer level of specificity for people than for common objects. The advantage of drawings over photographs in emphasizing critical features would seem to be greater for internal features that are harder to remember (Rock, Halper, \& Clayton, 1972) than for overall shape. So, a priori, faces seem to provide an even stronger test of the informativeness and representativeness of photographs, as opposed to drawings, than common objects.

If photographs are in fact perceived as being more characteristic of their targets, are remembered better, and are identified faster than caricatures, then how may we account for the widespread intuition that caricatures capture the essence of an individual better than photographs? It may be that different observers are struck by different caricatures of the same public figure. Thus, there may be agreement that a caricature can in principle capture a likeness better than a spontaneous photograph, but disagreement that a particular caricature has succeeded in that. Many subjects did think that some caricatures were superior to some photographs, and the variances of ratings for the caricatures were in every case higher than the variances for the photographs. Even when the target is the President of the United States, and the caricatures are produced by prominent journalistic cartoonists, there is considerable lack of agreement on exaggeration of features (Goldman \& Hagen, 1978). The only empirical support cited on behalf of the "caricature as a superstimulus" hypothesis has been the Ryan and Schwartz (1956) study. In that study, three objects in one of four positions were presented tachistoscopically at increasing exposures; the subjects' task was to reproduce the positions of elements of the objects. "Cartoon" drawings were superior to photographs for the switches and valves, but not for fingers of the hands. According to the photographs, the machines containing the switches and valves were very complex and detailed. Unlike the photographs, the cartoon drawings simply left out the parts of the machines whose positions were not to be imitated; thus, it was easier to search for the relevant parts since the irrelevant ones were not there. This could not be done for the hand, for which photographs were superior, since that would have meant omitting fingers. It seems unlikely that subjects would have judged the cartoon drawings to be better representations of the machines than the photographs, since the cartoons eliminated so many features of the machines. Also, the Ryan and Schwartz task did not assess object identification or memory. In retrospect, their experiment did not provide good support for the idea that a caricature is a "superstimulus."

Cursorily viewed, the finding that pictures that are more characteristic of a person are also better recognized than less representative pictures might seem to contradict the experiments reported by Light, Kayra-Stuart, and Hollander (1979). Their subjects rated a homogeneous group of yearbook photographs of young males for typicality. In recognition tests of memory for these photographs, performance was better for the atypical faces. The difference between the present experiment and the Light et al. experiment is a type-token difference. We presented one of two tokens for each of many types (Sadat, Nixon, Gistard D'Estaing, etc.) and tested memory for the type as a function of which token, typical or atypical, had been presented. In the Light et al. experiment, a larger number of tokens of the same type were presented and memory for the tokens was tested. Representativeness or typicality, like other structures in memory, have a double-edged effect: Structure facilitates memory of a type, but causes interference in memory for tokens of the same type.

Why, then, are photographs, more representative stimuli, processed faster, and remembered better than caricature drawings? The findings of several studies suggest that the facilitation occurs at encoding. Loftus and Bell (1975) also found better recognition memory for photographs of naturalistic scenes than for drawings constructed from the photographs. With the same stimuli, but with lengthy exposures $(10 \mathrm{sec})$, Nelson, Metzler, and Reed (1974) found no differences between photographs and drawings. Initial recognition for both was at ceiling, but delayed recognition was not. Together, these studies indicate that once the stimuli have been well encoded, effects of the pictorial mode, photographs or drawings, vanish. The present unstable findings for recall may be similarly explained. Loftus and Bell found that details were encoded at a faster rate from photographs than from line drawings, presumably because there is a greater density of detail in photographs: the more details, the better the recognition memory. However, even when details were not encoded, photographs were superior to drawings. The judgments in the present study suggest that this part of the facilitatory effect of photographs may be due to their being more characteristic or typical of that which they represent than are drawings. Moreover, the results of the verification task suggest that photographs access stored memory representations or meaning faster than do drawings. Thus, the combination of greater detail and greater representativeness seems to account for the advantage photographs enjoy over drawings in recognition, recall, and retrieval. 


\section{REFERENCES}

AttNeave, F. (1954). Some informational aspects of visual perception. Psychological Review, 61, 183-193.

BAHRICK, H. P., \& BouCHER, B. (1968). Retention of visual and verbal codes of the same stimuli. Journal of Experimental Psychology, 78, 417-422.

BartLetT, F. C. (1932). Remembering. Cambridge: Cambridge University Press.

BiEDERMAN, I. (1981). On the semantics of a glance at a scene. In M. Kubovy \& J. R. Pomerantz (Eds.), Perceptual organization. Hillsdale, NJ: Erlbaum.

GiBson, E. J. (1969). Principles of perceptual learning and development. New York: Appleton-Century-Crofts.

Goldman, M., \& HAGEN, M. A. (1978). The forms of caricature: Physiognomy and political bias. Studies on the Anthropology of Visual Communication, 6, 30-36.

Hagen, M. A., \& Perkins, D. (1983). A refutation of the hypothesis of the superfidelity of caricatures relative to photographs. Perception, 12, 55-61.

KINTSCH, W. (1970). Models for free recall and recognition. In D. Norman (Ed.), Models of human memory. New York: Academic Press.

Light, L. L., Kayra-Stuart, F., \& Hollander, S. (1979). Recognition memory for typical and unusual faces. Journal of Experimental Psychology, 5, 212-228.

LoFTUS, G., \& BELL, S. M. (1975). Two types of information in picture memory. Journal of Experimental Psychology: Human Learning and Memory, 104, 103-113.

MinsKY, M. (1975). A framework for representing knowledge. In P. H. Winston (Ed.), The psychology of computer vision. New York: McGraw-Hill.

Nelson, T. O., Metzler, J., \& Reed, D. A. (1974). Role of details in the long-term recognition of pictures and verbal descriptions. Joumal of Experimental Psychology, 102, 184-186.
PERKINS, D. (1975). A definition of caricature and caricature and recognition. Studies in the Anthropology of Communication, 2, 1-24.

Perkins, D. N., \& Hagen, M. A. (1980). Convention, context, and caricature. In M. A. Hagen (Ed.), The perception of pictures: Vol. 1 . Alberti's window: The projective model of pictorial information. New York: Academic Press.

Posner, M. I., \& KeELE, S. W. (1968). On the genesis of abstract ideas. Journal of Experimental Psychology, 77, 353-363.

ReEd, S. K. (1973). Psychological processes in pattern recognition. New York: Academic Press.

Rock, I., HALPER, F., \& Clayton, T. (1972). The perception and recognition of complex figures. Cognitive Psychology, 3, 655-673.

Rosch, E. (1978). Principles of categorization. In E. Rosch \& B. B. Lloyd (Eds.), Cognition and categorization. Hillsdale, NJ: Erlbaum.

Rosch, E., \& MERvis, C. (1975). Family resemblances: Studies in the internal structure of categories. Cognitive Psychology, 7, 573-605.

Rosch, E., Mervis, C., Gray, W., Johnson, D., \& Boyes-Braem, P. (1976). Basic objects in natural categories. Cognitive Psychology, 6, 382-439.

RUMElhart, D. E. (1981). Schemata: The building blocks of cognition. In R. Spiro, B. Bruce, \& W. Brewer (Eds.), Theoretical issues in reading comprehension. Hillsdale, $\mathrm{NJ}$ : Erlbaum.

Ryan, T. A., \& SchwarTz, C. B. (1956). Speed of perception as a function of mode of representations. American Journal of Psychology, 69, 60-69.

TVERSKY, B. (1973). Encoding processes in recognition and recall. Cognitive Psychology, 5, 275-287.

TVERSKY, B. (1974). Eye fixations in prediction of recognition and recall. Memory \& Cognition, 2, 275-278.

(Manuscript received June 1, 1984; revision accepted for publication July 24, 1984.) 